\title{
HEART RATES DURING FEMALE PHYSICAL EDUCATION LESSONS
}

\author{
T. HALE, M.Sc., and FIONA BRADSHAW, B.Ed.
}

Bishop Otter College, Chichester, Sussex

\section{INTRODUCTION}

Physical fitness is an important pre-requisite for optimum physical, mental and social well-being (WHO 1968). The development of fitness is an objective peculiar to the physical education curriculum and is based on the biological principle, first proposed by Roux a century ago, that organs are both maintained and developed by functional stress. Minimum levels of stress have been recommended by many authors (Karvonen et al, 1957; Roskamm, 1967; Wilmore, 1974), but evidence of the actual intensity of a physical education lesson is scarce. However the development of miniaturised recording equipment now makes it possible to monitor physical activity and compare the actual responses with the prescribed minimum.

This pilot study uses heart rate $(\mathrm{fH})$ as the index of intensity and describes the reactions of two groups of girls during physical education lessons.

\section{METHODS}

Seventeen subjects took part; 10 female physical education students chosen at random (PE) aged 19-20 years, and 7 school-girls (SG) aged $12-16$ years, regarded by the school staff as enthusiastic participants in physical education lessons.

Heart rates were recorded in two ways; (A) the habitual physical activity of the PE group only was monitored over two separate 36 hour periods with the SAMI/HR device (Baker et al, 1967). The recording cells were changed so that mean $\mathrm{fH}$ was obtained during work (i.e. timetabled sessions), leisure and sleep; (B) activity during 24 practical sessions (17 for the PE group, 7 for the school-girls) was monitored by a Parkes telemeter. Heart rates were recorded on to tape and subsequently replayed through a Washington pen-recorder; the 15 beat method (Åstrand and Rodahl, 1970) was used to obtain minute by minute $\mathrm{fH}$.

The activities monitored depended on the timetable and availability of subjects and investigators; they included 5 gymnastic, 6 games, 1 dance and 5 Union games sessions for the PE group, and 1 keep-fit, 2 athletics, 2 netball, and 2 badminton sessions for the SG group.

The Cochran and Cox approximation of student ' $t$ '-test (Ferguson, 1966) was used to test the significance of the difference between means.

\section{RESULTS}

PE Group

a) SAMI results

The data from both recording periods appear in Table I. The results are not significantly different.

TABLE I

Means and S.D.'s of fH (b.min) During Habitual Physical Activity of the P.E. Group

$\begin{array}{cccc} & \text { Work } & \text { Leisure } & \text { Sleep } \\ \text { I } & & & \\ & 93.6 & 87.2 & 61.4 \\ & \pm 3.98 & 3.97 & 2.10 \\ & & & \\ & 92.8 & 91.6 & 61.9 \\ & \pm 4.60 & 3.61 & 2.20\end{array}$

\section{b) Telemeter results}

A total of 854 minutes of activity was monitored, with the breakdown as follows; gymnastics 241 minutes, games 319 minutes, dance $\mathbf{3 0}$ minutes and Union games 264 minutes. Mean $\mathrm{fH}$ and duration of the activity are summarised in Table II.

\section{TABLE ॥}

Means and S.D.'s of Duration of and $\mathrm{fH}$ During Telemetred Sessions of the P.E. Group

\begin{tabular}{lrr} 
& $\begin{array}{c}\text { Time } \\
(\mathbf{m i n})\end{array}$ & \multicolumn{1}{c}{$\begin{array}{l}\mathrm{fH} \\
(\mathbf{b} \cdot \mathbf{m i n})\end{array}$} \\
Gym & 48.2 & \\
& \pm 16.6 & 106.3 \\
& & 16.0 \\
Games & 53.2 & 121.6 \\
& \pm 22.0 & 16.9 \\
Union & 52.8 & 124.6 \\
Games & \pm 20.7 & 6.9
\end{tabular}

The only significant difference is between $\mathrm{fH}$ during gym and Union games $(p<0.05)$. 


\section{SG Group}

The telemetry data for the seven school girls is summarised in Table III.

\section{TABLE III}

Means and S.D.'s of Duration of and $\mathrm{fH}$ During Telemetred P.E. Lessons of the S.G. Group

$\begin{array}{rl}\begin{array}{c}\text { Time } \\ (\min )\end{array} & \begin{array}{l}\text { fH } \\ \text { (b. } \min )\end{array} \\ & \\ 25.1 & 129.7 \\ \pm 7.7 & 12.3\end{array}$

The mean duration of the lessons was clearly less than the $\mathrm{PE}$ group, and although mean $\mathrm{fH}$ was higher than for any of the PE group sessions the difference was only significant during gymnastics $(p<0.02)$.

\section{DISCUSSION}

The understandable assumption that the PE group would have a level of activity of above average is not supported by the mean $\mathrm{fH}$ derived from the SAMI recordings. Comparisons with other student groups, shown in Table IV, show this clearly.

\section{TABLE IV}

Mean fH (b.min) During Habitual Physical Activity of Student Groups

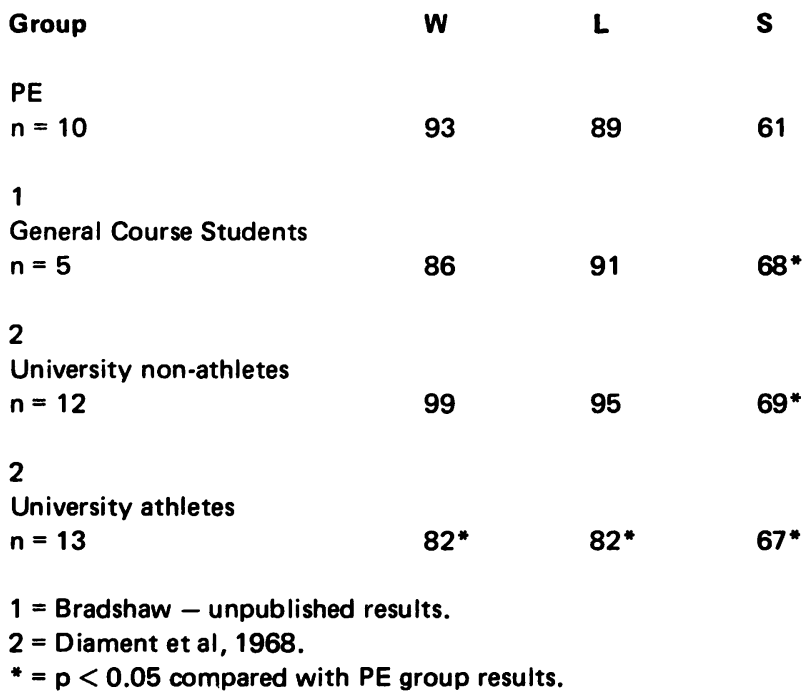

The University athletes appear to be the least active, but since trained athletes tend to have lower $\mathrm{fH}$ at rest and for a given work load an alternative to the mean $\mathrm{fH}$ is needed. If work and leisure $\mathrm{fH}$ are related to sleeping $\mathrm{fH}$ (Diament et al, 1968) the ratios, given in Table V, indicate that the PE group is the most active.

\section{TABLE V}

Mean W/S, L/S Ratios of Student Groups

$\begin{array}{ll}\text { Group } & \text { W/S } \\ \text { PE } & 1.52 \\ \text { General Course } & 1.26 * * \\ \text { University Non-Athletes } & 1.43 \\ \text { University Athletes } & 1.44 \\ & \\ * *=p<0.01 \text { compared with PE group results }\end{array}$

This result is not entirely unexpected, but gives limited information on the value of particular physical education lessons as agents for organic development. Karvonen suggests a minimum of approximately 30 minutes continuous whole body activity producing $\mathrm{fH}>$ 140 b.min, 5 times a week. Clearly the PE group's mean working $\mathrm{fH}$ of 93 b.min falls short of the prescribed minimum. But it is possible that $\mathbf{3 0}$ minutes of strenuous activity went undetected in the 8 hour recording period. An example illustrates this point. Assume a mean working $\mathrm{fH}$ of 90 b.min over 8 hours recording; add 30 minutes of training at $\mathrm{fH} 140$ b.min; the result is an $\mathrm{fH}$ of 92.9 b.min for the whole period.

Monitoring individual sessions should be more in formative, but averaging $\mathrm{fH}$ obtained by telemetry may also disguise the true stress of physical education session. The results show that mean $\mathrm{fH}$ during particular activities rarely exceeded 140 b.min, but this may be the result of wide variations in recording time. $A$ graphical display of minute by minute $\mathrm{fH}$ (Figures $1-3$ ) enable the total time that $\mathrm{fH}$ exceeds the training threshold to be calculated and thus give a better measure of the intensity of the session.

Using this approach peak $\mathrm{fH}$ clearly exceeded minimum levels but the total time seldom approaches the suggested 30 minutes in any one session. Out of the $\mathbf{8 5 4}$ minutes of PE group activity that were monitored, $\mathrm{fH}$ exceeded 140 b.min for a total of 140 minutes, about a quarter of the recommended time. Indeed, during six sessions $\mathrm{fH}$ never exceeded 140 b.min. 

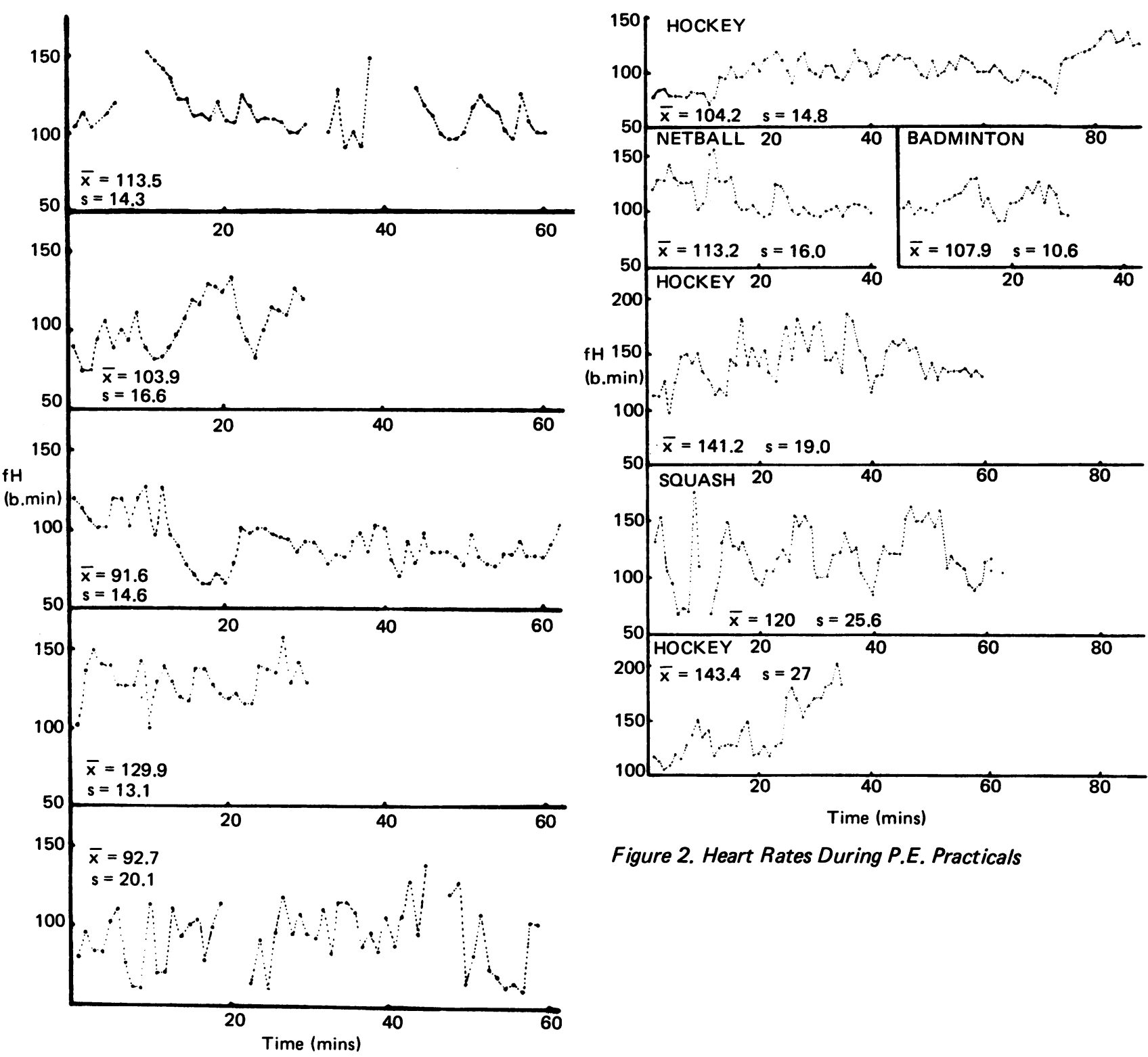

Figure 2. Heart Rates During P.E. Practicals

Figure 1. Heart Rates during Gymnastics. 


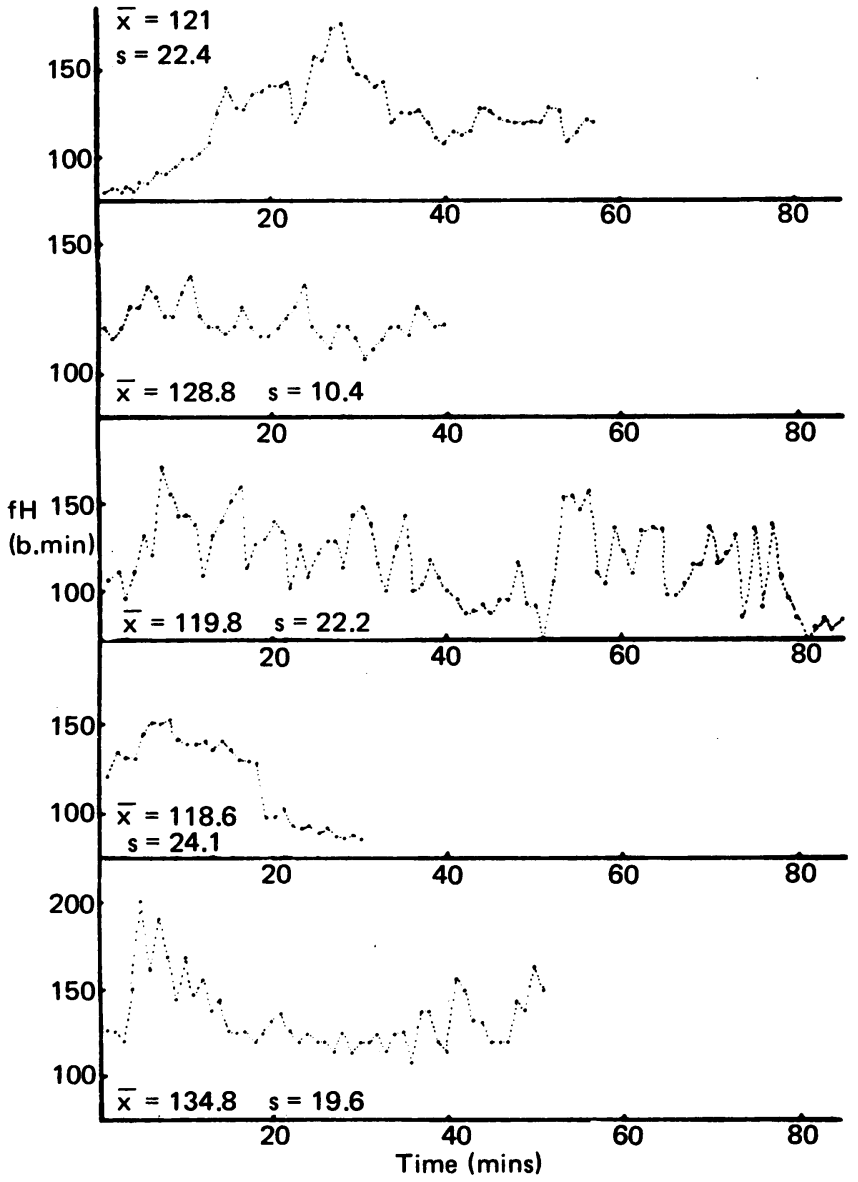

Figure 3. Heart Rates During Union Games

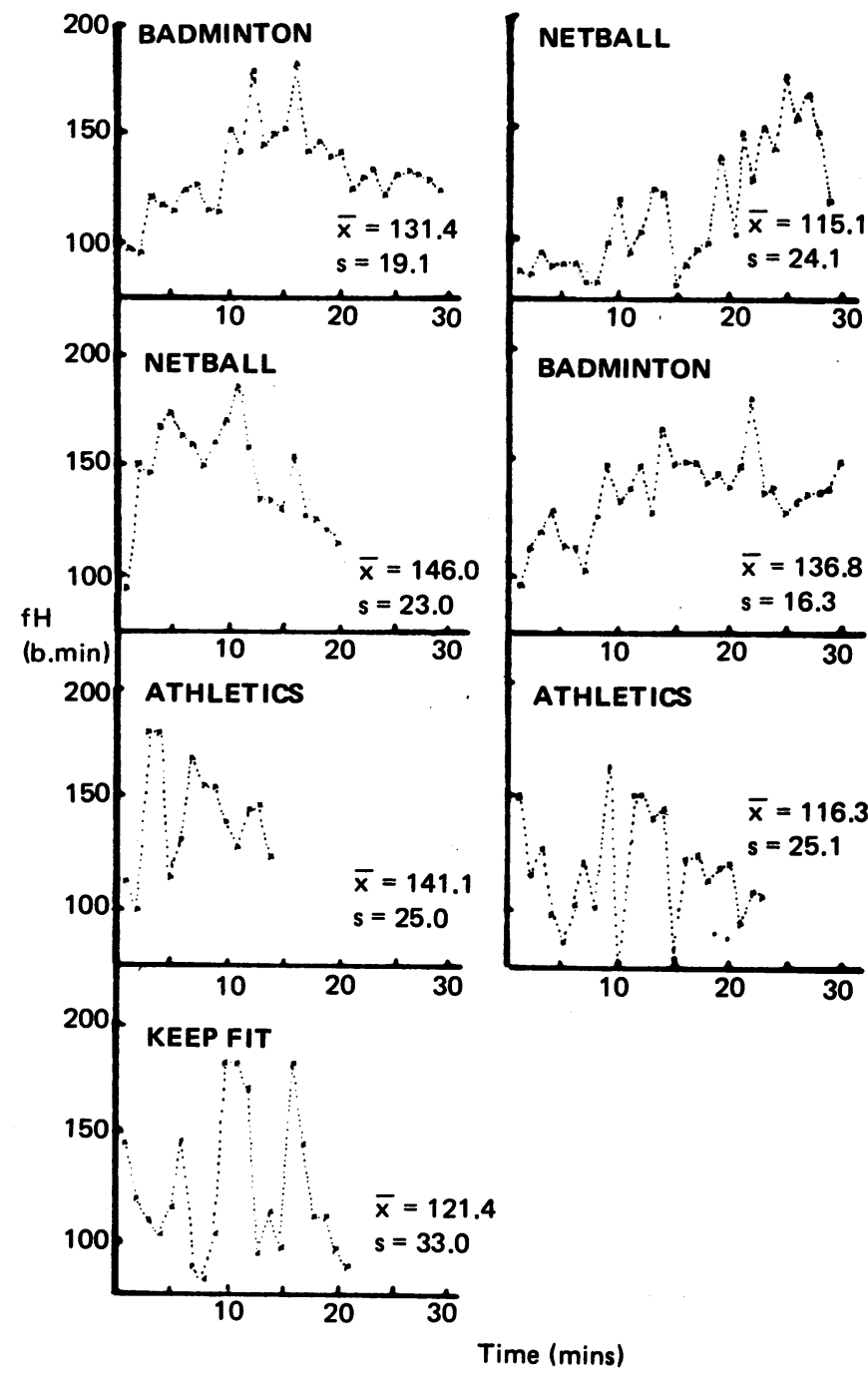

Figure 4. School Girl Heart Rates during P.E. Lessons

This evidence suggests that the physical education sessions monitored were not physiologically demanding enough to promote organic development to any marked degree. It is possible that neither the institutions, nor the individuals are representative but clearly further work in this area is necessary if physical education is to retain the unique quality it claims.

\section{ACKNOWLEDGEMENTS}

We would like to thank all the students, school-girls and staff who took part in this study for their willing co-operation. teacher-training are atypical, spending time observing and discussing rather than striving for organic improvement. This may be so, but the data from the SG group (Figure 4) are not markedly different. Out of the 176 minutes observed $\mathrm{fH}$ exceeded 140 b.min for 61 minutes and Roskamm's criterion for 13 minutes. 


\section{REFERENCES}

Åstrand, P. O., and Rodahl, K., 1970. Textbook of Work Physiology, McGraw-Hill, London.

Baker, J. A., Humphrey, S. J. E. and Wolff, H. A., 1967. Socially acceptable monitoring instruments (SAMI), J.Physiol., 188: 4.

Diament, M. L., Goldsmith, R., Hale, T. and Kelman, G. R., 1968. On the assessment of habitual physical activity, J.Physiol., 200: 44-5 p.

Ferguson, G. A., 1966. Statistical Analysis in Psychology and Education, McGraw-Hill, London.

Karvonen, M. J., Kentola, E. and Mustala, D., 1957. The effects of training on heart rate. Am.Med.Exp.Fenn. $35: 309$.

Roskamm, H., 1967. Optimum patterns of exercise for healthy adults. Canad.Med.Assoc.J., 96: 12.

Wilmore, J. H., 1974. Individual exercise prescription. Amer.J.Cardiol., 33: 6, 757.

World Health Organisation, 1968. Exercise tests in relation to cardio-vascular function, Tech.Rept. Ser. No. 388, Geneva. 